\title{
Chronic Hemodialysis Patients; Special Group for Hepatitis C Elimination Programs in Iran
}

\author{
Hamidreza Karimi-Sari, ${ }^{1,2,3}$ and Seyed Moayed Alavian ${ }^{2,3,{ }^{*}}$ \\ ${ }^{1}$ Student Research Committee, Baqiyatallah University of Medical Sciences, Tehran, Iran \\ ${ }^{2}$ Baqiyatallah Research Center for Gastroenterology and Liver Diseases (BRCGL), Baqiyatallah University of Medical Sciences, Tehran, IR Iran \\ ${ }^{3}$ Middle East Liver Disease (MELD) Center, Tehran, Iran \\ "Corresponding author: Seyed Moayed Alavian, Baqiyatallah Research Center for Gastroenterology and Liver Diseases (BRCGL), Baqiyatallah University of Medical Sciences, \\ Tehran, IR Iran. Tel: +98-2188945186, Fax: +98-2188945188, E-mail: alavian@thc.ir \\ Received 2017 March 18; Accepted 2017 May 06.
}

Keywords: Hemodialysis, Hepatitis C, Elimination, Screening

\section{Dear Editor,}

Recently world health organization (WHO) announced a global program to eliminate Hepatitis $\mathrm{C}$ virus (HCV) in the era of new direct acting antiviral drugs (DAAs) by 2030 (1). Finding and curing infected patients seems to be the most important step to reach the goal of HCV elimination (2). Iran has been categorized as a low endemicity country and prevalence of HCV infection is less than $0.5 \%$ in the general population (3). Of the 162 chronic hemodialysis patients (CHD), 11 patients (6.8\%) had HCV infection in a study by Makhlough et al., which has been published recently in your journal (4). The prevalence of HCV infection was 10 times more than the general population of Iran in patients with CHD of Makhlough et al. study. Since massscreening of the general population for HCV infection is not cost-effective, screening people with higher risk of HCV infection should be considered as a priority. Thus patients undergoing CHD seem to be a special group for HCV elimination in Iran.

Recent studies also showed that new DAAs are welltolerated in CHD patients with sustained virological response (SVR) rate of up to $100 \%(5,6)$. Today, accurate and low-cost generic DAAs are generally available in Iran (7). Also treating HCV infection is strongly recommended before kidney transplantation to increase the patients' survival (8). Infection with HCV was associated with all-cause mortality in a large cohort of patients with CHD (9).

The study of Makhlough et al. also showed that HCVAntibody (HCV-Ab) does not have enough accuracy for HCV screening in patients with CHD (4). Hence, real-time polymerase chain reaction (PCR) to find HCV-RNA should be considered for HCV screening in patients with CHD.

Finding and curing HCV infected cases among CHD pa- tients should be considered as a priority to reach the goal of HCV elimination and increase their survival.

\section{Footnotes}

Authors' Contribution: Both authors contributed equally in this manuscript.

Conflict of Interests: Authors declared no conflict of interests.

Funding/Support: There is no financial support.

\section{References}

1. Lancet T. Towards elimination of viral hepatitis by 2030 . Elsevier; 2016 .

2. Hesamizadeh K, Sharafi H, Rezaee-Zavareh MS, Behnava B, Alavian SM. Next Steps Toward Eradication of Hepatitis C in the Era of Direct Acting Antivirals. Hepat Mon. 2016;16(4):37089. doi: 10.5812/hepatmon.37089. [PubMed: 27275164].

3. Mirminachi B, Mohammadi Z, Merat S, Neishabouri A, Sharifi AH, Alavian SH. Update on the prevalence of hepatitis $\mathrm{c}$ virus infection among iranian general population: A systematic review and meta-analysis. Hepat Mon. 2017;17(2).

4. Makhlough A, Mahdavi M, Maleki I, Davoodi L, Mousavi T, HasaniMansoor SH, et al. The prevalence of hcv infection in hemodialysis population and compared elisa and pcr methods for detecting of hcv infection. Nephro-Urol Mon. 2017;In press(In press) doi: 10.5812/numonthly.45144.

5. Abad S, Vega A, Hernandez E, Merida E, de Sequera P, Albalate M, et al. Universal Sustained Viral Response to the Combination of Ombitasvir/Paritaprevir/Ritonavir and Dasabuvir with/without Ribavirin in Patients on Hemodialysis Infected with Hepatitis C Virus Genotypes 1 and 4.Am J Nephrol. 2017;45(3):267-72. doi: 10.1159/000454819. [PubMed: 28166520].

6. Saab S, A. Jimenez M , N. Bau S, Choi G, Durazo FA, M. El-Kabany $\mathrm{M}$, et al. Use of Sofosbuvir-Based Treatment of Chronic Hepatitis C in Liver Transplant Recipients on Hemodialysis. J Clin Gastroenterol. 2017;51(2):167-73. doi: 10.1097/MCG.0000000000000640. [PubMed: 27548734]. 
7. Alavian SM, Hajarizadeh B, Bagheri Lankarani K, Sharafi H, Ebrahimi Daryani N, Merat S, et al. Recommendations for the Clinical Management of Hepatitis $C$ in Iran: A Consensus-Based National Guideline. Hepat Mon. 2016;16(8):40959. doi: 10.5812/hepatmon.guideline. [PubMed: 27799966].

8. Einollahi B, Alavian SM. Hepatitis $C$ virus infection and kidney trans- plantation: a review for clinicians. Iran J Kidney Dis. 2010;4(1):1-8. [PubMed: 20081297].

9. Kalantar-Zadeh K, Kilpatrick RD, McAllister CJ, Miller LG, Daar ES, Gjertson DW, et al. Hepatitis $C$ virus and death risk in hemodialysis patients. J Am Soc Nephrol. 2007;18(5):1584-93. doi: 10.1681/ASN.2006070736. [PubMed: 17429053]. 